\title{
A CONTRIBUIÇÃO DO PROJETO BERÇÁRIO DE HACKERS NA ALFABETIZAÇÃO MATEMÁTICA DE CRIANÇAS EM FASE PRÉ-OPERATÓRIA
}

\author{
Emanuela Schmidt Alves ${ }^{1}$, Juliana Martins Chaves ${ }^{1}$, Eliel Maximino Decol ${ }^{2}$, \\ Adriano Canabarro Teixeira ${ }^{2}$, Evandro Luís Viapiana ${ }^{2}$ \\ ${ }^{1}$ Faculdade de Educação (FAED), Universidade de Passo Fundo (UPF) - \\ Caixa Postal 611 - CEP 99001.970 - Bairro São José - Passo Fundo - RS - Brazil \\ ${ }^{2}$ Instituto de Ciências Exatas e Geociências (ICEG), Universidade de Passo Fundo \\ (UPF) - Caixa Postal 611 - CEP 9900.1970 - Bairro São José - Passo Fundo - RS - \\ Brazil \\ emanuelaschmidt@hotmail.com, juuchaaves@gmail.com, \\ elieldecoll@gmail.com, teixeira@upf.br, viapiana@upf.br
}

\begin{abstract}
This article describes a research carried out with the Berçário de Hackers project promoted by the Prefeitura Municipal de Passo Fundo with the support of the Universidade de Passo Fundo. The activity serves children of 5 and 6 years of early childhood education. A qualitative training research developed together with a class of 25 students from a Municipal School of Passo Fundo, as a developed tool, such as a mathematical literacy, which consists of constructing concepts of logic, arithmetic, and geometry by children through the knowledge gained during the experience of unplugged computing and the playful use of Scratch Jr.
\end{abstract}

Resumo. $O$ presente artigo descreve a pesquisa realizada junto ao projeto Berçário de Hackers promovido pela Prefeitura Municipal de Passo Fundo com o apoio da Universidade de Passo Fundo. A atividade atende crianças de 5 e 6 anos da educação infantil. A pesquisa de cunho qualitativo será desenvolvida junto a uma turma de 25 alunos de uma Escola Municipal de Passo Fundo pretende-se analisar as habilidades desenvolvidas, como a alfabetização matemática, esta que consiste em construir conceitos de lógica, aritmética e geometria pelas crianças através das experiências realizadas durante a experienciação da computação desplugada e do uso lúdico do Scratch $J r$.

\section{Introdução}

Segundo Jean Piaget e sua teoria sobre o desenvolvimento humano, as crianças na idade de 5 e 6 anos encontram-se na chamada fase Pré-Operatória, que abrange crianças entre 2 e 7 anos. Essa fase é marcada pela emergência da linguagem, considerada uma condição necessária, mas não unicamente suficiente ao desenvolvimento, pois nela acontece a reorganização da ação cognitiva que não ocorre pela linguagem.

Segundo o autor, "de 4 a 7 ou 8 anos, aproximadamente, constitui-se, em continuidade íntima com o precedente, um pensamento, um pensamento intuitivo cujas 
VI Congresso Brasileiro de Informática na Educação (CBIE 2017)

Anais do XXIII Workshop de Informática na Escola (WIE 2017)

articulações progressivas conduzem ao limiar da operação." (PIAGET apud MOREIRA, 2015, p. 99)

A emergência da linguagem traz mudanças importantes em aspectos cognitivos, sociais e afetivos de uma criança, possibilitando interações individuais e fornecendo capacidade de trabalhar com representações que a fazem relacionar com a realidade vivida. Apesar das crianças apresentarem condições de trabalhar de uma forma lógica e coerente, essa fase ainda é caracterizada pelo egocentrismo, apresentando uma forma desequilibrada da realidade.

Segundo Ocsana Danyluk em seu livro “Alfabetização Matemática - o cotidiano da vida escolar", a criança desde cedo, com a soma de fatores e vivências, começa construir sua alfabetização matemática, compreendendo os códigos para poder se expressar com os números. Para a construção desse conceito é necessário iniciar-se com as primeiras noções de aritmética, geometria e lógica. A aritmética segue na linha de quantidade e construção de esquemas. A lógica consiste na classificação e seriação, construindo gradativamente o raciocínio transdutivo ao da lógica concreta, até chegar à lógica formal. Por sua vez, a geometria trabalha com a construção do espaço.

Porém, é de suma importância salientar que esses três conceitos não se constroem individualmente, mas sim em conjunto, interagindo na generalidade cognitiva, podemos chamar-se de interdisciplinaridade, pois se constitui em um todo. A autora aponta que "As crianças, ao compararem situações, objetos, números, letras e outros aspectos que aparecem em suas experiências vividas, constroem novos conhecimentos em que se estabelecem semelhanças, diferenças e relações." (DANYLUK, 1998, p.202)

Acredita-se que a programação de computadores tem potencial para o desenvolvimento e reconhecimento do conceito de números. Entretanto, ao se trabalhar com crianças na fase pré-operatória e não alfabetizadas, uma das estratégias passíveis de adoção neste processo é a Computação Desplugada que consiste no desenvolvimento de atividade sem o computador para o ensino de fundamentos da Ciência da Computação. A vantagem desse método é a possibilidade de se trabalhar a computação em lugares que não disponham de infraestrutura (energia elétrica, hardware ou software) necessária para a utilização de computadores e podem até ser ministradas por não especialistas em computação.

A computação desplugada é um método de ensino para criar circunstâncias que exploram ações relacionadas ao trabalho em equipe, a resolução de problemas e a criatividade. Jeannette M. Wing fala em seu artigo Computational Thinking que "O pensamento computacional é o que vem antes de qualquer tecnologia de computação pensamento de um ser humano, sabendo muito bem o poder da automação." (2012).

$\mathrm{Na}$ fase inicial de desenvolvimento da criança acredita-se no potencial da computação desplugada. Isso deve-se ao fato nem sempre tem-se acesso ao computador para a solução de problemas do cotidiano, que necessitam mais da prática pessoal do que do uso da tecnologia.

Por esse motivo, o Berçário de Hackers trabalha essencialmente com atividades voltadas à computação desplugada, desenvolvendo junto às crianças várias formas de ensino, seja por meio de jogos, de dinâmicas ou de metodologias que visam facilitar o aprendizado de maneira lúdica e interativa, sem necessitar diretamente do uso de um computador ou tablet, ou seja, da tecnologia. 
VI Congresso Brasileiro de Informática na Educação (CBIE 2017)

Anais do XXIII Workshop de Informática na Escola (WIE 2017)

Com referência a outras iniciativas brasileiras relativas a programação de computadores por crianças nesta faixa etária, encontramos:

O projeto MadCode, sediado em São Paulo, é um centro de Tecnologia Criativa voltado para jovens e crianças com idade de 5 a 17 anos, que oferece cursos de Programação e Robótica.

Foi encontrado também, nos Anais do XXI Workshop de Informática na Escola (WIE 2015), o artigo "Brinquedos de Programar na Educação Infantil: Um estudo de caso", que relata a experiência de um estudo com 15 crianças de 4 e 5 anos de idade, com o uso de brinquedos de programar na Educação Infantil, esses que realizam ações programadas pelas crianças. Assim de forma lúdica é introduzido conceitos matemáticos e resolução de problemas.

Posto isto, o objetivo desta pesquisa é identificar o potencial das atividades realizadas no interior do projeto Berçário de Hackers contribui para a alfabetização matemática nas crianças atendidas.

\section{Métodos}

Em 2014, iniciaram-se as atividades do projeto Escola de Hackers na fase piloto, da qual participaram alunos de $6^{\circ}$ ao $9^{\circ}$ ano do ensino fundamental, com idades entre $11 \mathrm{e}$ 14 anos. Abrangendo 21 escolas da rede municipal de educação, teve a participação de 312 alunos. A proposta da Escola de Hackers foi concretizada por meio de oficinas semanais - com aproximadamente duas horas de duração - nas escolas municipais, ministradas por monitores do projeto. Em 2015, o projeto foi ampliado, abrangendo também crianças de 5 a 6 anos, através do Berçário de Hackers, que consiste em uma derivação do projeto Escola de Hackers que atende alunos da educação infantil tendo, portanto, suas especificidades. As atividades do Berçário de Hackers são organizadas em 3 espaços distintos descritos a seguir.

Sala Log: ambiente onde as crianças realizam atividades visando o aprendizado de conceitos matemáticos, os quais auxiliarão na programação de computadores. Neste ambiente são usados blocos lógicos, quebra-cabeças, jogos matemáticos e materiais diversos. Para que as crianças possam explorar os comandos do scratchJr. na prática de forma lúdica e interativa antes de começar a programar nos tablets, foram construídos em uma impressora 3D, pelo grupo do berçário de Hackers que participou dos trabalhos do ano de 2015, os blocos de programação do ScratchJr.

Sala Tec: temos neste ambiente um espaço descontraído, com banquinhos, tapetes e almofadas no chão para que as crianças possam manusear, praticar e desenvolver as habilidades nos tablets e posteriormente pratiquem a programação com o ScratchJr.

LabComp: no terceiro ambiente, as crianças podem escolher atividades ou jogos de seu interesse (sempre com uma determinada limitação pré estabelecida pelos organizadores), tendo um tempo livre para jogar, pintar e brincar nos computadores. Os monitores vão observando as potencialidades e habilidades das crianças com os computadores e a autonomia das mesmas, sempre acompanhando e orientando nas atividades.

Ao iniciar-se o Berçário de Hackers de 2017, foi desenvolvido um teste com as crianças para obter-se mais conhecimento sobre o que já se havia de saberes prévios 
sobre o reconhecimento de formas geométricas, de contagem, de motricidade fina e, por fim, de noções de lateralidade. O mesmo teste foi aplicado para uma turma de mesma faixa etária, mas que não irá participar do projeto, obtendo-se assim dados que serão comparados no final do projeto, quando um novo teste será aplicado aos participantes e aos não participantes do projeto, permitindo a comparação da evolução dos diferentes grupos. Com a aplicação dos testes percebeu-se que há uma dificuldade na área de números, concluindo-se que no ano de 2017 o foco principal do projeto será a questão da alfabetização matemática.

Neste sentido, durante o ano serão trabalhados com as crianças participantes do projeto os conceitos de geometria, lógica e aritmética, como já foi exposto com vistas a um processo auxiliar de desenvolvimento da alfabetização matemática do grupo, que, junto com as vivências já obtidas fora do projeto poderão agregar para uma melhor compreensão em relação a construção dos saberes e, também, para um contato facilitador com o meio digital.

Uma concepção frequente na educação infantil no grau de escolarização em que eles se encontram, é a necessidade do uso de materiais concretos para trabalhar com a matemática. Com base nesse conceito, será trabalhado no $1^{\circ}$ semestre do ano a questão da aritmética, através do ensino dos números até o 9. Serão utilizados jogos de encaixe, onde a criança conta quantas figuras existem e precisa encontrar o número correspondente para encaixar. Também serão usadas tampinhas de garrafas, palitos de picolé e outras matérias alternativos para trabalhar-se a quantificação.

Juntamente com a questão aritmética será trabalhado o conceito de lógica através de jogos de labirinto, tabuleiros e jogos digitais on-line nos computadores e nos tablets. Um exemplo de jogo digital é conhecido como "mercadinho", onde o foco principal é a noção de contagem de dinheiro necessário para fazer compras no mercado. Já o conceito de geometria será trabalhado em uma sala de espelhos, auxiliando nos conceitos de espaço (direita, esquerda, cima, baixo), com desenhos do próprio corpo em um papel em tamanho real e, assim, serem direcionados a encontrarem os membros do corpo, com as noções de lateralidade. Além disso tudo, serão trabalhados com jogos educacionais que abrangem esses três conceitos.No segundo semestre do ano serão iniciadas as atividades no Scratch Jr, permitindo que as crianças tenham um melhor desenvolvimento na questão da alfabetização matemática. O software Scratch Jr é indicado para crianças na faixa etária das crianças participantes do Berçário de Hackers.

\section{Conclusões}

O teste inicial aplicado com as crianças participantes do Berçário de Hackers teve como objetivo obter um maior conhecimento acerca dos saberes das crianças relacionados a alfabetização matemática. $O$ teste foi composto por atividades de lógica, de reconhecimento números, de formas geométricas e de localização no espaço. Ao analisar os teste foi possível perceber uma maior dificuldade na área da aritmética. Por isso, o projeto irá proporcionar às crianças experiências diretamente ligada a alfabetização matemática, com intenção de influenciar positivamente na construção do conhecimento. 
VI Congresso Brasileiro de Informática na Educação (CBIE 2017)

Anais do XXIII Workshop de Informática na Escola (WIE 2017)

\section{References}

[DANYLUK, O.] Alfabetização Matemática: as primeiras manifestações da escrita infantil. Porto Alegre: Sulina, Passo Fundo: Ediupf, (1998).

[MOREIRA, M. A]. Teorias De Aprendizagem. 5 e.d. São Paulo: E.P.U., (2015).

[RAABE, A.; RODRIGUES, A. J.; SANTANA A.; VIEIRA, M.V.; ROSÁRIO, T. do; CARNEIRO, A. C.] Brinquedos de programar na Educação Infantil: Um estudo de caso. [artigo]. Disponível em: <http://www.br-ie.org/pub/index.php/wie/article/view/4985>. Acesso em: 23 ago. 2017.

[WING, Jeannette.] Computational Thinking, (2012). Disponível em $<$ https://goo.gl/NPTZWS $>$. Acesso em 02/06/2017. 